\title{
Impactos da mecanização na produtividade agrícola agregada da cana-de-açúcar no estado de São Paulo de 2007 a 2013
}

\author{
Impacts of mechanization on sugarcane agricultural productivity in \\ the state of São Paulo from 2007 to 2013 \\ Nicole Rennó Castro ${ }^{1}$ (D), Leandro Gilio² (B), Gabriel Costeira Machado ${ }^{3}$ (1) \\ 'Departamento de Ciências Econômicas, Universidade Federal de São João Del Rei (UFSJ), São João Del Rei (MG), Brasil. E-mail: \\ rennonicole@ufsj.edu.br \\ ${ }^{2}$ Centro de Agronegócio Global (Insper Agro Global), Insper, São Paulo (SP), Brasil. E-mail: leandrog3@insper.edu.br \\ 3Programa de Pós-graduação em Economia Aplicada, Escola Superior de Agricultura "Luiz de Queiróz" (ESALQ), Universidade de \\ São Paulo (USP), Piracicaba (SP), Brasil. E-mail: gmcosteira@usp.br
}

\begin{abstract}
Como citar: Castro, N. R., Gilio, L., \& Machado, G. C. (2022). Impactos da mecanização na produtividade agrícola agregada da cana-de-açúcar no estado de São Paulo de 2007 a 2013. Revista de Economia e Sociologia Rural, 60(2), e235496. https://doi.org/10.1590/1806-9479.2021.235496
\end{abstract}

Resumo: A produtividade da cana-de-açúcar em São Paulo reduziu cerca de 5\% entre 2007 e 2013, contrastando com o desempenho de outras culturas no estado. No mesmo período, o percentual de área com colheita mecanizada no estado aumentou de 46,6\% para 83,7\%. Há alguma discussão entre especialistas sobre a possibilidade de que a mecanização teria impactado negativamente a produtividade da cultura, mas não há na literatura um estudo que tenha mensurado quantitativamente esse efeito agregado. Esta pesquisa buscou contribuir para preencher essa lacuna, mensurando o efeito da mecanização sobre a produtividade da cana-de-açúcar no estado de São Paulo no período de 2007 a 2013. Para isso, foi estimada uma função de produção com controle climático, utilizando um modelo de efeitos fixos aplicado a uma base de dados em painel por microrregiões. Os resultados do estudo apontaram para a existência de um impacto negativo do avanço da mecanização para quatro mesorregiões do estado: 6,6\% em Ribeirão Preto, 9,7\% em Araraquara, 6,2\% em Piracicaba e 3,4\% em Assis. No entanto, não houve um impacto agregado significativo do avanço da mecanização no estado como um todo. As regiões para as quais foram estimados impactos negativos significativos têm parte relevante da área canavieira localizada em áreas declivosas.

Palavras-chave: cana-de-açúcar, mecanização, produtividade.

Abstract: In contrast to the performance of other crops in the state, sugarcane productivity decreased 5\% between 2007 and 2013 in the state of São Paulo. In the same period, the percentage of mechanized harvesting area in the state increased from $46.6 \%$ to $83.7 \%$. There is some discussion among experts about the possibility that mechanization would have negatively impacted productivity, but there is no study in the literature that has quantitatively measured this aggregate effect. This study sought to contribute to fill this gap, by measuring the effect of mechanization on sugarcane productivity in the state of São Paulo in the period from 2007 to 2013. Therefore, a production function with climate control was estimated using a fixed effects model applied to a panel database by microregions. The results of the study showed the existence of a negative impact of the advance of mechanization in four mesoregions of the state: $6.6 \%$ in Ribeirão Preto, 9.7\% in Araraquara, $6.2 \%$ in Piracicaba and 3.4\% in Assis. However, there was no significant aggregate impact when assessing the state as a whole. The regions for which significant negative impacts have been estimated have a relevant part of the sugarcane area located in areas with greater slopes.

Keywords: sugarcane, mechanization, productivity.

\section{INTRODUÇÃO}

A história recente do setor sucroenergético brasileiro foi marcada por importantes transformações que impactaram significativamente em sua estrutura e técnicas de produção e influenciaram diretamente seu desenvolvimento. Fatos como a desregulamentação do setor 
pós-década de 1990, o surgimento dos veículos bicombustíveis em 2003 e os processos de aquisições, fusões e internacionalização da produção contribuíram para a reorganização do setor e para uma rápida elevação da oferta e da demanda de açúcar e etanol, com a consequente expansão significativa da produção de cana-de-açúcar (Moraes \& Zilberman, 2014; Silva et al., 2019). Essa expansão, por sua vez, se deu, sobretudo, via incorporação de área pelo cultivo da cana por meio da substituição de áreas de pastagens e de outros tipos de lavouras temporárias e permanentes (Caldarelli \& Gilio, 2018; Silva et al., 2019).

Esse crescimento trouxe preocupações com relação aos possíveis impactos, como ambientais e sociais, devidos à emissão de gases pelo processo de queima como método de despalha da cana e às condições de saúde do trabalhador rural associado à atividade agrícola (Gilio, 2015; Silva et al., 2019). Como resultado, regulações sobre a questão das queimadas foram discutidas e firmadas desde meados de 2000, destacando-se o Decreto Federal no 2.661 de 1998, que estabeleceu a eliminação gradual da queima no Brasil, e, no estado de São Paulo, principal estado produtor e foco do presente estudo, o Protocolo Agroambiental, assinado em 2007 e que antecipou a eliminação da queima para 2014 nas áreas com declividade inferior a 12\% e para 2017 nas demais áreas (Brasil, 1998; Moraes, 2007; Silva et al., 2019).

Como efeito imediato, houve a queda significativa da produtividade média do trabalho no corte manual da cana crua em relação ao corte manual associado ao processo de queima, gerando pressão sobre a necessidade de mecanização da colheita (Moraes, 2007; Silva et al., 2019). Algumas evidências na literatura científica e técnica indicam que o início do processo de mecanização pode ter exercido impactos negativos sobre a produtividade agrícola, contribuindo para a estagnação da produtividade da cana no mesmo período (Baccarin, 2015; Nyko et al., 2013; Milanez et al., 2012).

O uso de máquinas, além de demandar altos investimentos iniciais, também pode afetar o desenvolvimento da cultura ao induzir a compactação do solo e potencialmente danificar os colmos remanescentes com o tráfego de máquinas nas lavouras (Dias \& Sentelhas, 2018; Souza et al., 2014; Braunack \& McGarry, 2006). Especificamente, a danificação da estrutura do solo afeta sua capacidade de reter e conduzir ar, água e nutrientes, eventualmente, levando à redução de produtividade (Usaborisut \& Sukcharoenvipharat, 2011). Ademais, segundo Milanez et al. (2012), além da compactação do solo, a redução da produtividade relacionada ao processo de mecanização pode decorrer da menor densidade de plantas por área plantada e da maior altura relativa em que o colmo é cortado pelas colheitadeiras. Nyko et al. (2013) também destacam que o cenário para a cana-de-açúcar tem agravantes frente ao que se observa para os cereais, relacionados tanto à complexidade biológica e genética da cultura quanto aos grandes desafios nas operações de plantio e, principalmente, de colheita, em função das elevadas quantidades de massa envolvidas, que demandam colhedoras expressivamente mais robustas.

Especificamente, entre 2007 e 2013 a produção de cana em São Paulo expandiu 32\%, com aumento de $39 \%$ da área colhida e redução de $5 \%$ da produtividade da terra (Instituto Brasileiro de Geografia e Estatística, 2018); ao mesmo tempo, o percentual de área mecanizada no estado passou de 46,6\% em 2007 para 83,7\% em 2013 (Canasat, 2019).

Porém, além da mecanização da atividade, diversos fatores também podem ter afetado a produtividade. Iniciou-se um ciclo de crise e supressão de investimentos na cadeia sucroenergética devido a aspectos como a política de controle de preços da gasolina executada pela Petrobras desde 2006, a baixa previsibilidade das políticas energéticas brasileiras, as desonerações promovidas sobre os combustíveis fósseis para controle inflacionário, o aumento dos custos trabalhistas, o alto endividamento das usinas e as restrições à aquisição de terras por estrangeiros no Brasil (Solowiejczyk \& Costa, 2013; Moraes \& Zilberman, 2014; Gilio \& Castro, 2017).

Segundo Marin et al. (2016), a crescente demanda global por etanol, combinada às preocupações em relação a possíveis efeitos da conversão de áreas de pastagem e florestais para a produção 
agrícola, impôs ao Brasil o desafio de elevar a produção sem necessariamente aumentar a área de cultivo, sendo, então, a produtividade uma questão-chave. Esse cenário, combinado à importância do setor sucroenergético para o desenvolvimento da política de biocombustíveis nacional, torna a questão da produtividade imperativa no âmbito do planejamento energético e políticas ambientais.

Portanto, uma melhor compreensão da queda de produtividade verificada na cultura canavieira de modo geral nos últimos anos é fundamental. Este presente estudo tem como objetivo avaliar uma das possibilidades, ou, de modo mais específico, o efeito do avanço da mecanização sobre a produtividade agregada das lavouras de cana-de-açúcar. Especificamente, analisa-se o estado de São Paulo, considerando-se as mesorregiões, para o período de 2007 a 2013, para o qual estavam disponíveis os dados do Canasat.

Além dessa introdução, o presente artigo conta com mais cinco seções. A próxima seção apresenta a literatura recente sobre a questão da produtividade da cana-de-açúcar e sua relação com a mecanização. Em sequência, a seção 3 apresenta o modelo econométrico estimado e discute as estratégias empíricas adotadas. A seção 4 trata das fontes de informações e dos tratamentos aplicados aos dados. As últimas duas seções apresentam os resultados do estudo e as discussões e, então, as considerações finais.

\section{PRODUTIVIDADE DA CANA-DE-AÇÚCAR E MECANIZAÇÃO}

Não foi encontrado na literatura científica um estudo que tenha mensurado quantitativamente o impacto da mecanização na produtividade agregada da cana-de-açúcar no Brasil ou em São Paulo. Mas há estudos que avaliaram a questão da produtividade e da produção canavieira sob outras perspectivas, cujos resultados contribuíram para a presente discussão e ampararam a construção do modelo empírico.

Satolo \& Bacchi (2009) avaliaram os efeitos de choques de oferta e de demanda sobre a produção canavieira de São Paulo entre 1976 e 2006. Foram considerados choques de renda interna, choques de preços provenientes da demanda (preços dos subprodutos) e da oferta (preços da cana-de-açúcar) e choques de área plantada. Em relação à produtividade, os autores encontraram que $40 \%$ da variação histórica pôde ser atribuída a outras variáveis que não ela própria, sendo a principal o preço da cana-de-açúcar.

Dias \& Sentelhas (2018) avaliaram quais os principais fatores que limitam a produtividade da cana-de-açúcar em diversas regiões do Brasil, considerando déficit hídrico ou manejo. Os autores encontraram que a principal causa do gap de produtividade da cana-de-açúcar é o déficit hídrico, ao passo que o efeito do manejo depende da região e das práticas adotadas. Com relação ao estado de São Paulo, os autores trouxeram evidências de que a limitação de produtividade relacionada a manejo foi a menor frente às demais regiões avaliadas; ademais, as regiões leste e sul do estado também apresentaram os menores gaps relacionados ao déficit hídrico.

Sachs (2015) analisou os determinantes da produtividade da cana-de-açúcar no estado de São Paulo para o período de 1998 a 2009. A autora encontrou que a produtividade atingível (proxy de fatores climáticos), o estágio médio de corte e o preço da cana-de-açúcar foram os principais determinantes. Já a contribuição das variáveis biológicas (introdução de novas variedades), que era foco do estudo, não foi significativa no período - o que, segundo a autora, pode decorrer do baixo nível de adoção de novas variedades no período, sendo que a maior parte da área com cana-de-açúcar no estado ainda era ocupada com variedades desenvolvidas nos anos 1980.

Segundo Nyko et al. (2013), a tendência de estagnação ou queda da produtividade da cultura após seu ápice em 2007 pode ser explicada por condições climáticas adversas, pela baixa renovação de canaviais e pelo avanço da mecanização. Os resultados desses autores tomam por base entrevistas com especialistas do setor. 
Especificamente em relação à mecanização, tem-se que o tráfego de máquinas pesadas, sobretudo em períodos úmidos, pode afetar o desenvolvimento da cultura ao induzir a compactação do solo e potencialmente danificar os colmos remanescentes (Dias \& Sentelhas, 2018; Souza et al., 2014; Braunack \& McGarry, 2006). Segundo Usaborisut \& Sukcharoenvipharat (2011), o uso intensivo de máquinas pode danificar a estrutura do solo, afetando sua capacidade de reter e conduzir ar, água e nutrientes, eventualmente levando à redução de produtividade. Ademais, segundo Milanez et al. (2012), além da compactação do solo, a redução da produtividade relacionada ao processo de mecanização pode decorrer da menor densidade de plantas por área plantada e da maior altura relativa em que o colmo é cortado pelas colheitadeiras. A questão da compactação do solo desencadeada pela mecanização foi observada em município do estado de São Paulo, Nova Europa (Aguilera Esteban et al., 2019), bem como em outros países em que houve a transição para o processo de mecanização da cultura de cana-de-açúcar (Usaborisut \& Sukcharoenvipharat, 2011; Tullberg et al., 2007). Por outro lado, não se deve desprezar o efeito danoso da queima de palha sobre o solo. Conforme Otto et al. (2011), essa estratégia afeta a temperatura e a retenção de água, a densidade, a estabilidade, a infiltração, a quantidade de nutrientes, entre outros.

Não obstante, estudos têm mostrado a vantagem do tráfego controlado de máquinas como uma solução para mitigar os impactos das máquinas sobre o solo (Tullberg et al., 2007; Aguilera Esteban et al., 2019). Entre os estudos focados no Brasil, Scheidl et al. (2015) realizaram um estudo de caso focado nas operações de colheita e encontraram que a mecanização implicaria em um consumo adicional de 228 milhões de litros de diesel pelo setor sucroenergético. Souza et al. (2014) conduziram um experimento em uma lavoura canavieira em Pradópolis, São Paulo, para avaliar o impacto de diferentes estratégias de manejo quanto ao controle de tráfego sobre o desenvolvimento radicular, a produtividade e a qualidade tecnológica da cana-de-açúcar. Os autores encontraram que os sistemas de gestão com controle de tráfego levaram a um aumento de 18,72\% da produtividade. Aguilera Esteban et al. (2019), por meio de um experimento no município de Nova Europa, estado de São Paulo, encontraram que a adoção de sistema de tráfego controlado associado ao espaçamento duplo entre fileiras tem o potencial de preservar a qualidade física do solo e aumentar a produtividade da cana-de-açúcar.

Deve-se ressaltar, como apontam Milanez et al. (2012), que a tendência apontada por especialistas de redução da produtividade diante da mecanização pode se reverter à medida que os produtores se adaptarem às novas condições, atingindo os níveis de conhecimento e destreza necessários. Os resultados de estudos realizados para outros países em que o processo de mecanização da cultura é menos recente podem contribuir para corroborar essa análise de Milanez et al. (2012).

Schmitz et al. (2020) analisaram dados do estado de Louisiana, nos Estados Unidos, cuja produção de cana-de-açúcar é a segunda maior do país. Foi considerado o período de 1911 a 2019. Além de considerar o efeito das variedades genéticas de cana-de-açúcar sobre o crescimento da produção de cana-de-açúcar e de açúcar, os autores também verificam o impacto da adoção da colheita mecanizada. Para essa análise, foram considerados dois períodos relevantes: 1945 , momento em que se deu a adoção de máquinas para colheita, período em que a mão de obra se fazia limitada devido ao fim da Segunda Guerra Mundial; e 1995, momento em que há uma mudança na tecnologia adotada na mecanização. Os resultados do primeiro caso se mostraram não significativos estatisticamente; ao passo que a adoção da mecanização no passado recente, caracterizada pelo uso de colheitadeiras, mostrou-se estatisticamente significante para explicar o aumento da produção de açúcar, mas não de cana-de-açúcar. Analisando a Flórida, entre 1950 e 2018, Schmitz e Zhang (2019) encontraram que a mecanização impactou positivamente a produtividade, o que seria um resultado das melhorias relevantes sobre a tecnologia associada.

Na próxima seção, é introduzido o modelo econométrico estimado e as estratégias empíricas adotadas são discutidas à luz dessa revisão da literatura. 


\section{MODELO ECONOMÉTRICO E ESTRATÉGIAS EMPÍRICAS}

Como visto na seção anterior, a literatura aponta diversos fatores que afetam a produtividade da cana-de-açúcar, relacionados a clima, manejo e mercado (Cardoso et al., 2018; Dias \& Sentelhas, 2018; Sachs, 2015; Marin \& Carvalho, 2012). Especificamente, são relatados determinantes como clima, tipo de solo, variedade da cana-de-açúcar, práticas de manejo, uso de insumos, existência de pragas e doenças, preços, custos e políticas públicas (Cardoso et al., 2018; Marin \& Carvalho, 2012). Segundo Marin e Carvalho (2012), que analisaram São Paulo entre as safras 1990/1991 e 2005/2006, 43\% da variabilidade da eficiência produtiva da cana-de-açúcar se devem ao clima, 15\%, ao solo e $43 \%$ se devem a fatores socioeconômicos, bióticos e de manejo.

Neste estudo, a produtividade da cana-de-açúcar é avaliada com o enfoque econômico, e o modelo econométrico proposto baseia-se no modelo teórico da função da produção CobbDouglas padrão, com incorporação de controle climático. O modelo é estimado utilizando dados em painel, em que as unidades de corte transversal são as microrregiões do estado de São Paulo, observadas anualmente de 2007 a 2013. A estratégia empírica e a escolha das variáveis adaptam para o caso em estudo e sua respectiva disponibilidade de dados às estratégias utilizadas mais recentemente em trabalhos como os de McArthur \& McCord (2017), Auffhammer et al. (2012) e Levinsohn \& Petrin (2003), que por sua vez têm como base fundamental a análise de funções de produção agrícolas de Hayami \& Ruttan (1970).

$\mathrm{Na}$ literatura, os seguintes estudos com abordagem similar e focados na cana-de-açúcar foram encontrados: i) Silva et al. (2019), que avaliaram os efeitos da variabilidade climática sobre a produção canavieira no estado da Paraíba; ii) Kumar et al. (2015), que avaliaram a influência de fatores climáticos e não climáticos na produtividade média da cana-de-açúcar na Índia; iii) Dlamini \& Masuku (2012), que avaliaram a produtividade de cana-de-açúcar de pequenos agricultores em Essuatíni; e iv) Nazir et al. (2013), que buscaram identificar os fatores que afetam a produção de cana-de-açúcar no Paquistão.

Especificamente, o modelo empírico estimado no estudo pode ser representado pela Expressão 1:

$y_{i t}=c_{i}+\varphi_{j} t+\beta_{1 j} m e c+\beta_{2 j} m d o+\beta_{3 j} p r e c+\varepsilon_{i t}$

A variável $y_{i t}$ representa a produtividade da terra, em toneladas por hectare, para cada microrregião $i$ e ano $t$. $O$ uso da produtividade da terra como variável dependente, frente ao uso da produção com inclusão do logaritmo da área como variável explicativa adicional, teve como objetivo simplificar o modelo e evitar possíveis problemas de endogeneidade relacionados à determinação simultânea da área colhida e da produção (Auffhammer et al., 2012; Mundlak, 2001).

A variável mec , expressa em percentual da área colhida sem queima, ou de forma mecanizada, é a variável explicativa de interesse (e proxy do estoque de capital na função de produção), sendo $\beta_{l j}$ os coeficientes estimados para cada mesorregião. A variável mdo representa o fator trabalho, expresso em número de vínculos de emprego por microrregião, sendo $\beta_{2 j}$ os coeficientes a serem estimados, também heterogêneos entre as mesorregiões.

A variável prec representa as precipitações totais no período crítico para a produtividade das safras (setembro a março), sendo $\beta_{3 j}$ os coeficientes estimados para as mesorregiões. Essa variável representa um choque exógeno e aleatório e, por hipótese, altamente correlacionado com a variável de interesse.

Das variáveis supramencionadas, com exceção da representativa da mecanização (expressa em percentual), todas foram utilizadas em seus logaritmos neperianos. Ainda na Equação 1, $c_{i}$ representa os efeitos fixos por microrregião, captando as características locacionais não 
observáveis e invariantes no tempo. Esse aspecto é essencial tendo em vista que fatores como qualidade do solo e potencial de erosão, considerados tipicamente invariantes no tempo, são determinantes-chave da produtividade agrícola.

Também foram incluídas tendências temporais anuais específicas a cada mesorregião $j, \varphi_{j} t$, sendo $\varphi_{j}$ os coeficientes estimados. Com isso, busca-se controlar para movimentos lineares não observáveis ou cujos dados não estão disponíveis com a desagregação ou período necessários e que podem ter afetado as produtividades das regiões no período.

Nesse ponto, devem-se destacar algumas limitações desse modelo. Primeiramente, como a variável dependente é medida em produção, e não em valor adicionado, o uso de insumos de consumo intermediário (como fertilizantes e defensivos) deveria ser incluído no modelo. Todavia, não existem informações sobre esse uso com o nível de desagregação regional e espaço temporal necessários. Em segundo lugar, como apontado na literatura, o manejo e os preços da cana-de-açúcar também são determinantes importantes da produtividade e poderiam contribuir para aprimorar a especificação estatística do modelo. Mas essas variáveis também não estão disponíveis de forma específica para as microrregiões paulistas e, em modelos de dados em painel, a inclusão de variáveis que variam no tempo, mas são constantes entre as unidades de corte transversal, não fornece informações adicionais, não sendo possível fazer uma distinção em relação ao controle temporal. Espera-se que parte dos efeitos de preço e de manejo seja captada por $\varphi_{j}$.

Para referência, a Figura 1 compara a evolução, no período em estudo, do preço da canade-açúcar no estado de São Paulo e do custo total de produção da cultura na região centro-sul. Como se observa, sobretudo entre 2008 e 2011, os preços cresceram de forma menos acelerada que os custos. Essa dinâmica, embora não possa ser captada explicitamente no modelo, também pode ter sido relevante para explicar a estagnação ou queda da produtividade da cultura no período - já que a situação financeira dos produtores deve afetar a intensidade dos investimentos no canavial. Conforme Silva \& Marques (2017), como a evolução dos custos não foi acompanhada pelo avanço dos preços, ocorreu uma situação de deterioração das margens econômicas; e, embora os preços tenham sido suficientes para cobrir despesas operacionais e depreciação, eles não superaram os custos totais (ainda que a cultura fosse viável no médio prazo, apresentava pouca lucratividade no longo prazo).

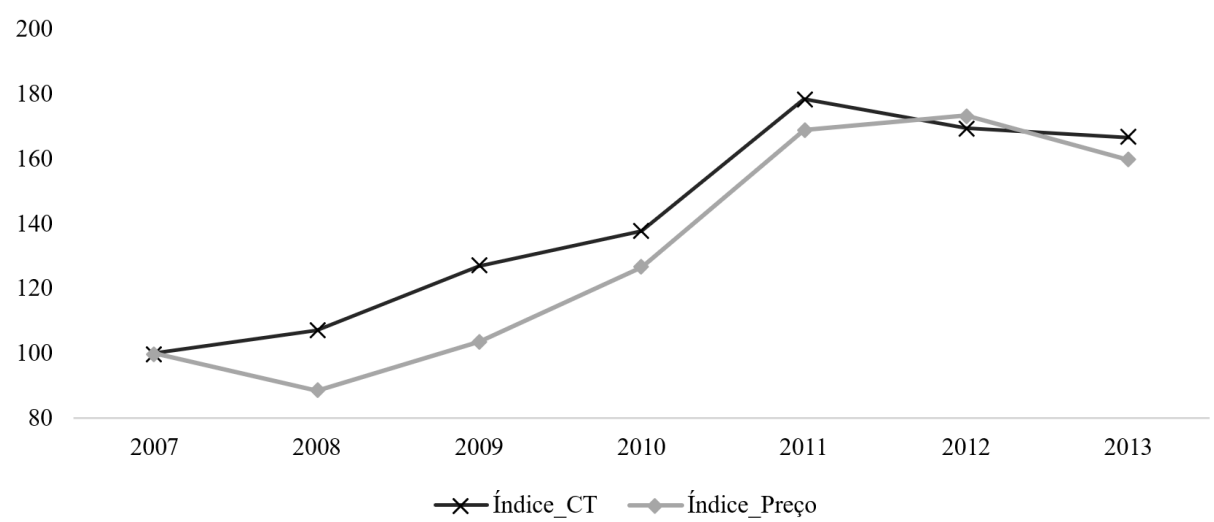

Figura 1 - Evolução, entre 2007 e 2013, do preço da cana (na esteira) em São Paulo e do custo total de produção da cultura. Fonte: Conselho de Produtores de Cana-de-Açúcar, Açúcar e Etanol do Estado de São Paulo (2020) e Silva \& Marques (2017)1.

1 Silva \& Marques (2017) apresentam a evolução dos custos do setor sucroenergético no Brasil entre as safras de 2007/2008 e 2014/2015, a partir de informações coletadas junto a produtores e usineiros. Na região centro-sul tradicional, cinco mesorregiões do estado de São Paulo são consideradas: Catanduva, Sertãozinho, Piracicaba, Araçatuba, Assis e Jaú. 
Retornando às estratégias econométricas, o modelo de efeitos fixos foi escolhido frente ao de efeitos aleatórios pelos motivos teóricos explicitados em sequência. Primeiramente, esse modelo permite que o painel de dados seja utilizado para estimar uma relação causal sob pressupostos mais fracos, ou quando o componente não observável e invariante no tempo é correlacionado com as variáveis explicativas (Cameron \& Trivedi, 2005). Ademais, uma fragilidade comum do modelo de efeitos fixos está no fato de que sua estimação é uma análise condicional - enquanto o modelo de efeitos aleatórios é uma análise marginal -, com a predição sendo possível apenas para as observações da amostra; no caso deste presente estudo, como a amostra coincide com a população, essa limitação não está presente (Cameron \& Trivedi, 2005).

Mesmo no estado de São Paulo, a heterogeneidade do setor produtor da cana-de-açúcar é elevada no espaço, com variações em fatores como nível tecnológico, estratégia de gerenciamento, tamanho das propriedades, entre outros. Por isso, justifica-se a especificação adotada considerando coeficientes heterogêneos para mesorregiões.

Quatro versões adicionais modificadas do modelo completo (Modelo 1) também foram estimadas. Na primeira especificação alternativa (Modelo 2), assume-se uma tendência temporal linear homogênea para o estado. Na segunda versão alternativa (Modelo 3), elimina-se o controle climático do modelo completo. Na terceira especificação (Modelo 4), o Modelo 1 é estimado por mínimos quadrados ordinários, não sendo incluídos os efeitos fixos. Na quarta e última versão alternativa (Modelo 5), assume-se um coeficiente homogêneo para a variável mecanização. A apresentação dos cinco modelos, com inclusões sequenciais de controles, buscou, além de avaliar a robustez dos coeficientes estimados de interesse, avaliar a importância dos efeitos fixos, temporais e climáticos e dos efeitos heterogêneos da mecanização entre as regiões.

\section{FONTES E TRATAMENTO DOS DADOS}

Os dados de mecanização foram obtidos, para o período de 2007 a 2013, no Canasat do Instituto Nacional de Pesquisas Espaciais (Inpe), que fez um mapeamento anual da colheita da cana utilizando imagens de satélite, baseado em Rudorff et al. (2010) e Aguiar et al. (2011). Foi utilizado o mapeamento anual por tipo de colheita, que classifica as áreas colhidas em dois grupos: com ou sem a queima da palha da cana-de-açúcar. Utilizando o software QGIS, os dados espaciais foram organizados de acordo com os municípios e microrregiões paulistas, de modo a se obter, para cada ano e unidade de análise, o percentual da área total com canade-açúcar que foi colhida sem queima.

Foram utilizadas informações adicionais, com base na especificação tradicional da função de produção com controle climático: área colhida e quantidade produzida de cana, mão de obra empregada nas lavouras e precipitação. Os dados de área colhida e quantidade produzida de cana foram obtidos na pesquisa Produção Agrícola Municipal (PAM) do Instituto Brasileiro de Geografia e Estatística (2018).

Quanto às informações sobre mão de obra empregada, utilizaram-se os microdados da Relação Anual de Informações Sociais (Rais) (Brasil, 2020). Importante destacar que os dados de emprego da Rais se referem apenas ao mercado de trabalho formal. Portanto, para o estudo de setores com alta informalidade, a referida base de dados pode não ser adequada. A alternativa consiste em utilizar dados das pesquisas domiciliares amostrais do IBGE, mas essas não possibilitam atingir níveis maiores de desagregação espacial. Nessa pesquisa, sendo o foco de análise a cultura canavieira, o uso da Rais não implica em distorções da realidade do setor, dado o alto nível de formalização do seu mercado de trabalho. Como visto em Gilio et al. (2019), em 2014 a informalidade no setor sucroenergético representou 12,1\% das 
ocupações, sendo 9,9\% no centro-sul. Ainda sobre os dados de emprego, assim como feito em Gilio et al. (2019), adotou-se uma forma diferente de classificação dos trabalhadores do setor sucroenergético entre os seus diferentes ramos de atividade. Esse procedimento será detalhado na próxima subseção.

Os dados de precipitação são de Xavier et al. (2016), que disponibilizaram uma base de dados completa com grids de alta resolução $\left(0,25^{\circ} \times 0,25^{\circ}\right)$ de dados diários. Os valores anuais de precipitação utilizados são a soma das precipitações totais mensais para os meses de setembro do ano anterior a março do ano corrente. Esse período pode ser considerado crítico para a produtividade em toneladas da lavoura, captando o período de plantio e crescimento vegetativo do ciclo médio de produção.

É preciso reforçar um detalhe importante em relação à estratégia de agregação espacial dos dados utilizada. Embora as informações utilizadas sejam disponíveis para municípios, optou-se por utilizar as microrregiões como unidades de corte transversal. Isso decorre de uma especificidade dos dados da Rais. As informações dos vínculos empregatícios da pesquisa são fornecidas pela empresa contratante, e pode ocorrer de o município associado ao emprego ser aquele onde está sediada a contratante, e não aquele em que o trabalhador atua na lavoura canavieira. A agregação de dados para microrregiões buscou minimizar possíveis vieses relacionados a essa questão. Testes de robustez foram realizados e trouxeram indicativos de que a hipótese está correta.

Embora os dados estejam estruturados para microrregiões, na estimação dos resultados, como visto na seção anterior, considerou-se coeficientes heterogêneos para as diferentes mesorregiões do estado - para poupar graus de liberdade e facilitar a interpretação dos resultados, tendo em vista que o estado é desagregado em 63 microrregiões, mas apenas 15 mesorregiões. A Figura 2 mostra as mesorregiões de São Paulo.

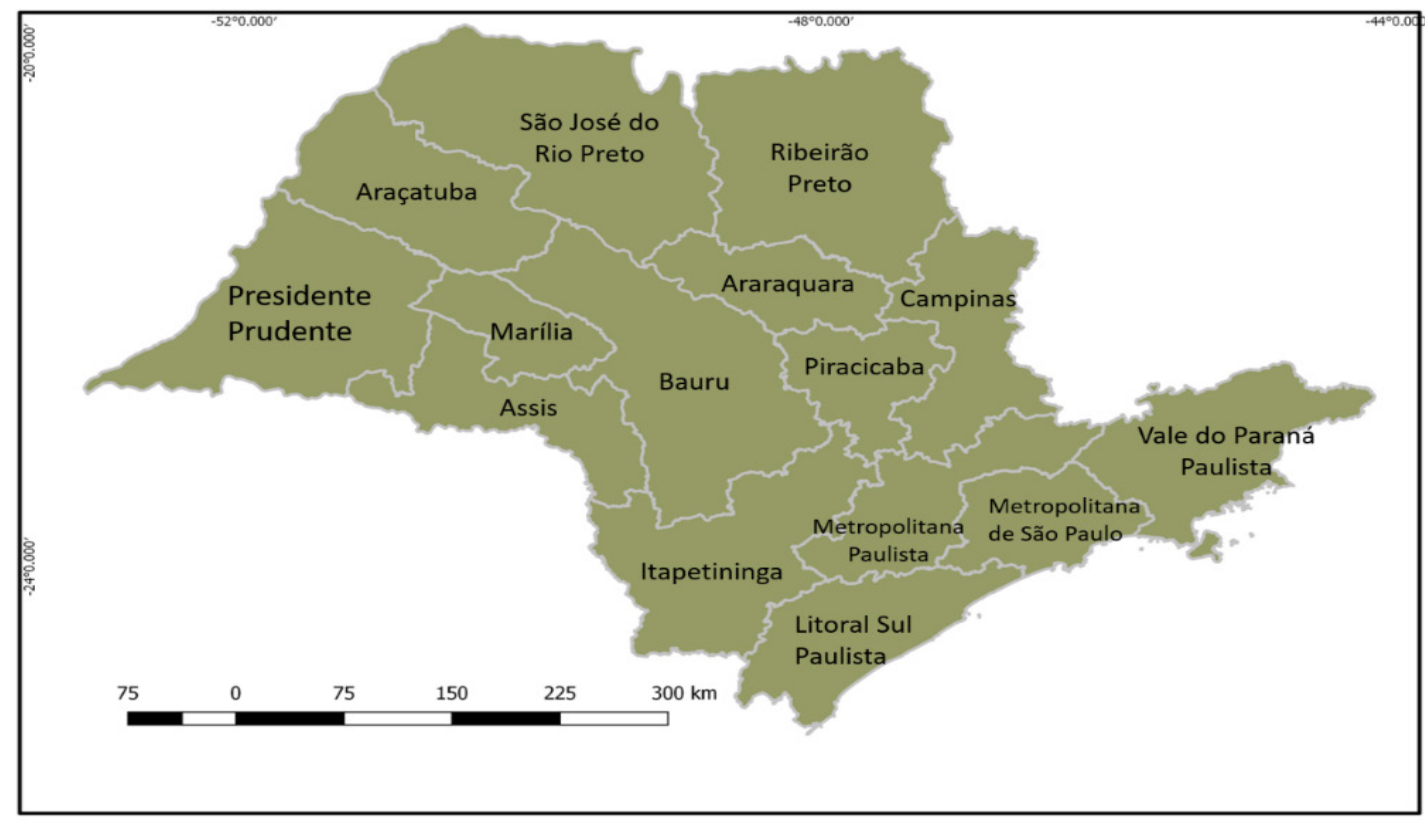

Figura 2 - Mesorregiões do estado de São Paulo. Fonte: Elaboração própria. 


\subsection{Tratamento e classificação dos dados da Rais}

Usualmente, a classificação de trabalhadores entre os diferentes setores de atividade é feita utilizando a Classificação Nacional de Atividades Econômicas (CNAE), como visto em Moraes (2007), Toneto-Junior \& Liboni, (2008) - entre os estudos voltados ao setor sucroenergético. No setor sucroenergético, as CNAEs envolvidas são a de cultivo de cana-de-açúcar e as de atividades industriais (produção de açúcar e etanol).

O problema central levantado por Gilio et al. (2019) é que, na Rais, a definição do código CNAE atrelado a cada trabalhador é feita a partir da atividade principal da empresa contratante, e a maior parte das usinas do setor produz uma proporção elevada da cana-de-açúcar que processa; especificamente na safra 2012/2013, esse percentual foi de 58,78\%. Essa elevada verticalização implica em um viés na classificação de trabalhadores entre os elos da cadeia utilizando apenas as CNAEs, já que muitos trabalhadores envolvidos na produção primária da cana-de-açúcar em empresas verticalizadas estariam classificados como pertencentes ao elo industrial. Gilio et al. (2019) propõe uma classificação alternativa, feita em duas etapas, e adotada neste estudo: i) selecionam-se os trabalhadores pertencentes às CNAEs relativas ao setor sucroenergético; ii) então, estes são reclassificados intrasetorialmente entre as atividades agrícolas e industriais por meio de suas ocupações dentro do setor, sendo utilizado o Código Brasileiro de Ocupações (CBO). Desse modo, é possível encontrar o número de trabalhadores atuantes diretamente na produção primária da cana. Essa mudança de classificação tem efeitos importantes. Em 2005, Moraes (2007), utilizando as CNAES, encontrou um total de 414.668 trabalhadores na atividade agrícola canavieira; Gilio et a. (2019), por sua vez, utilizando CNAEs e CBOs, encontrou que 795.410 trabalhadores atuavam na área agrícola do setor.

\section{RESULTADOS E DISCUSSÃO}

A Figura 3 mostra a evolução anual, para o estado de São Paulo como um todo, da área colhida, quantidade produzida, produtividade média por hectare e percentual da área mecanizada, para o período de 2007 a 2013. No período, a produção de cana no estado aumentou 32\%, crescimento atrelado ao aumento de $39 \%$ da área colhida, ao passo que a produtividade de terra reduziu 5\%. Ao mesmo tempo, o percentual de área mecanizada no estado passou de 46,6\% em 2007 para $83,7 \%$ em 2013. A queda da produtividade da cana contrasta com o desempenho de outras culturas, que têm alcançado ganhos relevantes em produtividade. Segundo informações da Companhia Nacional de Abastecimento (2019), a produtividade dos grãos aumentou 23,5\% no país entre as safras 2006/2007 e 2012/2013; em São Paulo, o crescimento foi de 33,6\%.

Além da defasagem da produtividade da cana em relação aos grãos, essa também está bastante aquém do seu potencial para o Brasil. Marin et al. (2016) estimaram que a produtividade média nacional representava $62 \%$ do potencial de produtividade estimado para condições de sequeiro, ou seja, há um gap de 38\%. Dias \& Sentelhas (2018) analisaram os gaps de produtividade da cana em diversas regiões do Brasil. Focando no estado de São Paulo, os autores encontraram que a influência das práticas de manejo na defasagem de produtividade é menor do que em outras regiões, o que seria explicado pela maior tradição do estado no cultivo, levando a práticas melhores. Ainda assim, entre as regiões paulistas avaliadas, o gap variou entre $80 \mathrm{t} / \mathrm{ha}$ (Itapetininga) e $125 \mathrm{t} / \mathrm{ha}$ (Votuporanga) - para referência, o maior gap encontrado no Brasil foi de 202 t/ha, em Petrolina-PE.

É importante mencionar que a produtividade da cultura no estado vinha de uma tendência ascendente, que parece ter um ponto principal de inflexão em 2010, conforme dados da PAMIBGE (Instituto Brasileiro de Geografia e Estatística, 2018). Focando no período anterior a essa inflexão, Marin \& Carvalho (2012) encontraram que a eficiência da produção canavieira paulista 
aumentou entre as safras 1990/1991 e 2005/2006, com o gap de produtividade reduzindo de expressivos 58\% para 42\%. Esse efeito, segundo os autores, se intensificou a partir de 2001/2002, provavelmente um resultado de maiores investimentos e adoções de tecnologia e da expansão para o oeste do estado, um reflexo do consumo crescente de etanol no Brasil no período.

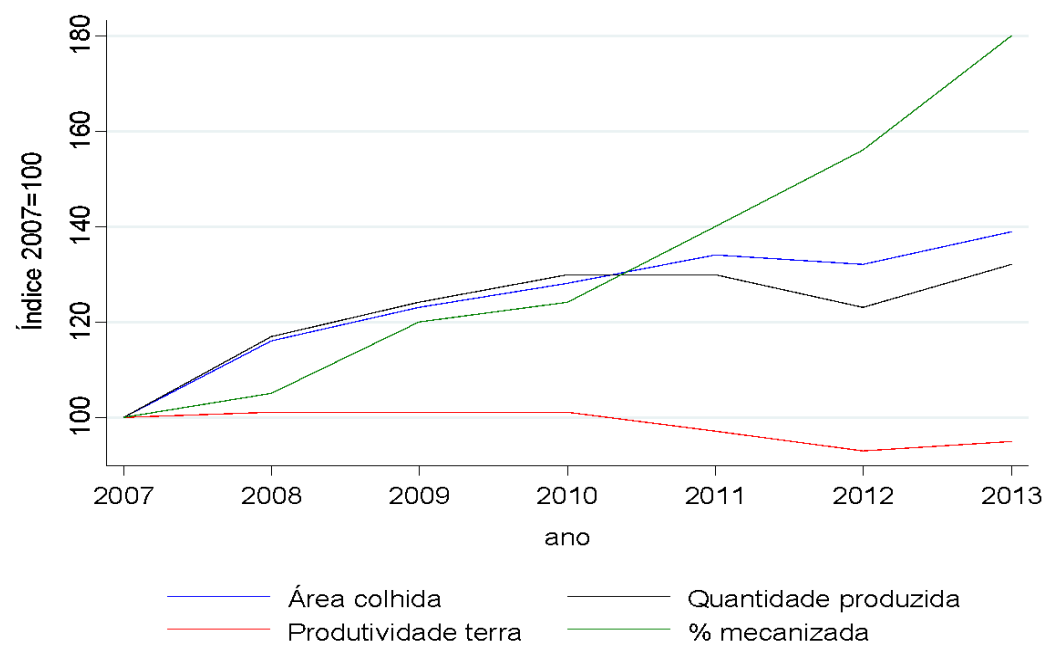

Figura 3 - Evolução da área colhida, quantidade produzida, produtividade da terra e percentual de área mecanizada no estado de São Paulo $(2007=100)$. Fonte: Elaboração dos autores com base em PAM-IBGE (Instituto Brasileiro de Geografia e Estatística, 2018) e Canasat (2019).

A Figura 4 mostra a distribuição dos percentuais de mecanização, por município paulista, em 2007, 2010 e 2013. Nota-se que, ao longo do período, a expansão da mecanização foi consistente na maioria dos municípios, com a maior parte apresentando percentual superior a $70 \%$ ao período final da análise. A análise da figura também permite notar que o avanço do processo de mecanização se intensificou expressivamente entre 2010 e 2013, período que converge com o de inflexão da tendência ascendente da produtividade supramencionado.

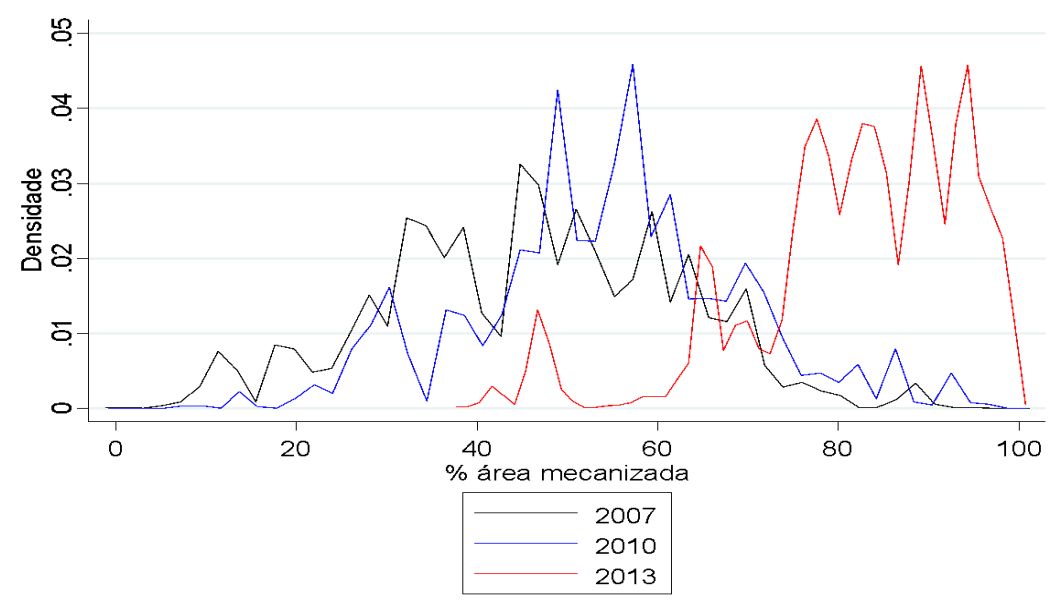

Figura 4 - Distribuição dos percentuais de mecanização nos municípios paulistas (2007, 2010 e 2013). * Função de densidade Kernel com a "regra de bolso de Silverman" para a escolha do bandwidth. Fonte: Elaboração dos autores com base em Canasat (2019). 
Ainda de forma descritiva, a Figura 5 retrata, para as mesorregiões de São Paulo, a produtividade (em quilogramas por hectare) e a participação da área com colheita mecanizada (em \%) em 2007, 2008, 2012 e 2013 - biênios inicial e final do período de análise. Pela análise da Figura 5a nota-se que, no biênio 2007-2008, as mesorregiões de São José do Rio Preto, Ribeirão Preto, Araçatuba, Marília e Itapetininga tinham produtividades superiores a 85 toneladas por hectare. Para essas regiões, houve redução importante no biênio 2012-2013. Reduções de produtividade também foram verificadas nas regiões de Presidente Prudente e Assis. Já para as regiões de Bauru, Araraquara, Piracicaba e Campinas, não houve uma queda aparente de produtividade na comparação entre 2007-2008 e 2012-2013, mas o patamar já era mais baixo no biênio inicial.

(a): produtividade

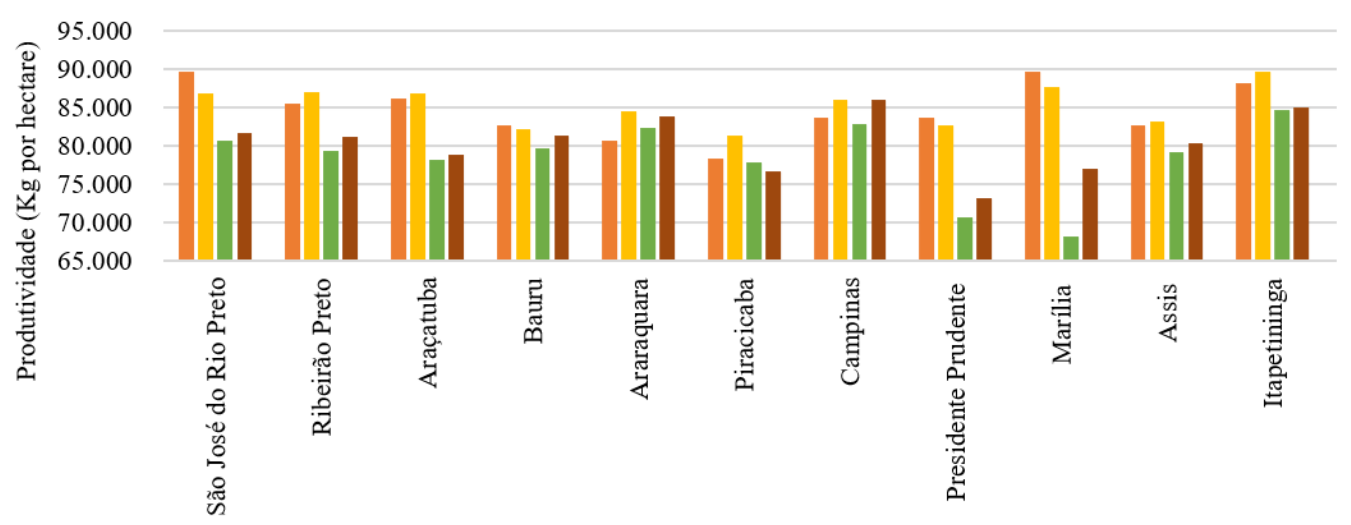

(b): percentual da área mecanizada

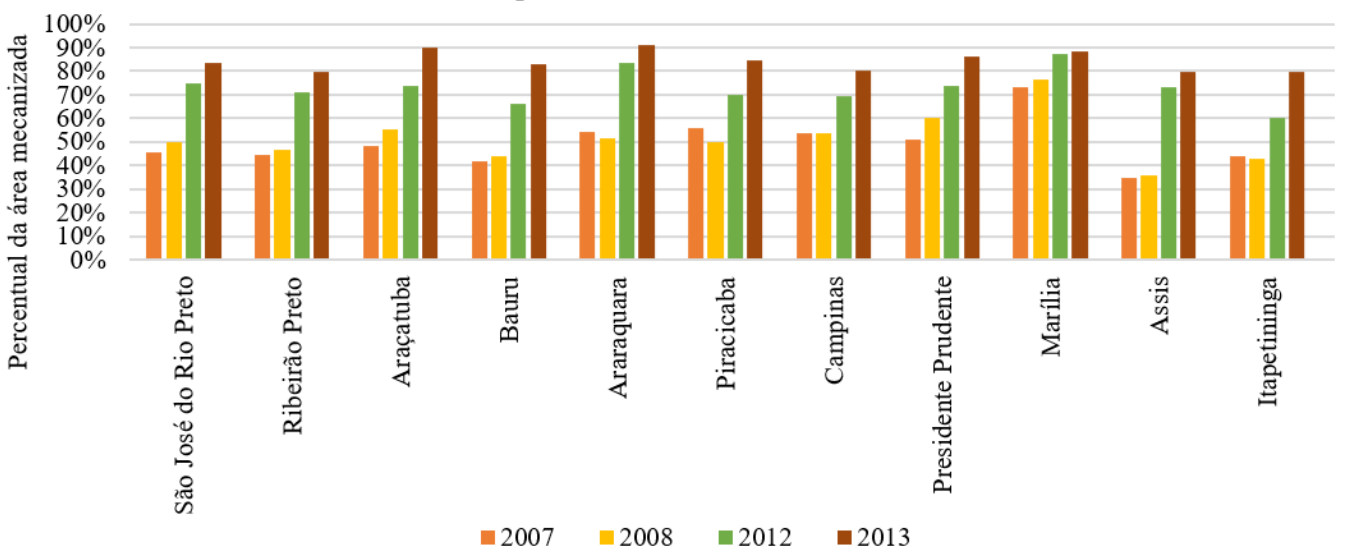

Figura 5 - Para as mesorregiões de São Paulo: produtividade (kg/ha) e da participação da área com colheita mecanizada (\%) em 2007, 2008, 2012 e 2013. Fonte: Elaboração dos autores com base em PAM-IBGE (Instituto Brasileiro de Geografia e Estatística, 2018) e Canasat (2019).

Logo, no período, as quedas mais intensas de produtividade foram verificadas sobretudo no oeste do estado, ao passo que na parte central houve relativa estabilidade. Os resultados de Dias \& Sentelhas (2018) mostram que os maiores gaps de produtividade relacionados a déficit hídrico, entre as regiões paulistas, estão nas parcelas ao norte e a oeste, em contraste às regiões de produção a leste e sul do estado. Por outro lado, Marin \& Carvalho (2012) apontam que mesmo no oeste paulista, região com déficit hídrico mais alto em São Paulo e de expansão mais recente da cultura, a produtividade da cana ainda é alta frente a outras regiões do país, como a Nordeste, onde o clima mais seco e quente e os solos mais empobrecidos prejudicam os rendimentos. 
Quanto às intensidades de mecanização - Figura $5 b$-, no biênio inicial as mesorregiões de Marília e Macro Metropolitana Paulista se destacavam com participação superior a $60 \%$ de áreas mecanizadas. Mas essas regiões em conjunto respondiam por apenas 1,2\% da área com cana no estado. Já a mesorregião de Assis, que representava 7\% da área com cana, detinha a menor taxa de mecanização no biênio, inferior a 40\%. Para as demais mesorregiões, havia alguma homogeneidade no grau de mecanização, com percentuais entre 40 e $60 \%$ da área. Em 2013, todas as mesorregiões detinham mais de 70\% da área mecanizada.

Conforme discutido na revisão apresentada na seção 2 deste estudo, os possíveis efeitos negativos da intensificação da substituição da colheita manual pela mecanizada sobre a produtividade envolvem o fato de que o tráfego de máquinas pesadas pode afetar a compactação do solo, assim como a menor densidade de plantas por área plantada e a maior altura relativa em que o colmo é cortado pelas colheitadeiras (Dias \& Sentelhas, 2018; Baccarin, 2015; Souza et al., 2014; Nyko et al., 2013; Usaborisut \& Sukcharoenvipharat, 2011; Braunack \& McGarry, 2006). Baccarin (2015) complementa que, com o excesso de palha deixado no campo, aumenta a ocorrência de problemas fitossanitários que influenciam na produção.

Embora essa análise descritiva traga indícios de um impacto negativo do avanço da mecanização sobre a produtividade das lavouras canavieiras, tendo em vista os movimentos concomitantes de avanço da mecanização e redução de produtividade da cultura, outros fatores provavelmente também influenciaram a produtividade no período.

A partir de 2009, o setor sucroenergético vivenciou um período de crise e cautela de investimentos, cenário que teria sido reflexo de fatores conjunturais que foram além da mecanização, como a política de controle de preços da gasolina e de desonerações sobre os combustíveis fósseis, a baixa previsibilidade de políticas energéticas, o aumento dos custos trabalhistas e as restrições à aquisição de terras por estrangeiros que limitaram investimentos (Gilio et al., 2019; Solowiejczyk \& Costa, 2013; Moraes \& Zilberman, 2014; Gilio et al., 2015; Gilio \& Castro, 2017). Com isso, entre 2008 e 2014 houve o fechamento de 64 usinas localizadas na região centro-sul do país, movimento atrelado às dificuldades financeiras enfrentadas no período e com prováveis efeitos sobre investimentos e consequentemente sobre a produtividade da cana (Santos et al., 2015).

Como visto em Satolo \& Bacchi (2009) e em Sachs (2015), o preço da cana-de-açúcar é determinante importante da produtividade, ao passo que o trabalho de Dias \& Sentelhas (2018) evidenciou a relevância do manejo. Considerando a evolução conjunta de preços e custos de produção em São Paulo no período em estudo, apresentada na Figura 1, verificou-se que, sobretudo entre 2008 e 2011, os preços cresceram de forma menos acelerada que os custos, 0 que potencialmente se refletiu negativamente na intensidade dos investimentos nos canaviais do estado. Além desses efeitos, a produtividade no período também foi afetada por condições climáticas adversas, notadamente em 2010 e 2011 (Nastari, 2012 apud Baccarin, 2015).

Os resultados das estimativas para os impactos da mecanização sobre a produtividade agregada da cultura da cana no estado de São Paulo são sumarizados na Tabela 1, para diferentes especificações. O modelo completo e preferido é aquele que consta na coluna 1, sendo a especificação do modelo expresso na Equação 1. Para testar a robustez dos resultados e avaliar a importância individual dos efeitos fixos, temporais e climáticos e dos efeitos heterogêneos da mecanização entre as regiões, são apresentados também os modelos das colunas de 2 a 5 , em que os controles são alternados sequencialmente. Na coluna 2, assume-se uma tendência temporal linear homogênea para o estado; na coluna 3, elimina-se o controle climático; na coluna 4, não são incluídos os efeitos fixos e, na última coluna, 5, assume-se um coeficiente homogêneo para a variável mecanização. 
Tabela 1 - Resultados empíricos: impactos da mecanização sobre a produtividade (2: tendência temporal linear homogênea; 3: sem controle climático; 4: sem efeitos fixos; 5: efeito homogêneo da mecanização)

\begin{tabular}{|c|c|c|c|c|c|}
\hline & 1 & 2 & 3 & 4 & 5 \\
\hline \multicolumn{6}{|c|}{ Mecanização } \\
\hline \multirow[t]{2}{*}{ - São Paulo (Estado) } & - & - & - & - & 0,0064 \\
\hline & - & - & - & - & $(0,0558)$ \\
\hline \multirow[t]{2}{*}{ - São José do Rio Preto } & $-0,1644$ & $-0,1573$ & $-0,1977$ & $-0,1017$ & - \\
\hline & $(0,1587)$ & $(0,1580)$ & $(0,1695)$ & $(0,1157)$ & - \\
\hline \multirow{2}{*}{ - Ribeirão Preto } & $-0,1880 * \star \star$ & $-0,1288$ & $-0,1846 * \star *$ & $-0,0194$ & - \\
\hline & $(0,0683)$ & $(0,0768)$ & $(0,0638)$ & $(0,1503)$ & - \\
\hline \multirow[t]{2}{*}{ - Araçatuba } & 0,0836 & $-0,0122$ & $-0,0100$ & $-0,0146$ & - \\
\hline & $(0,1545)$ & $(0,1239)$ & $(0,1515)$ & $(0,2048)$ & - \\
\hline \multirow[t]{2}{*}{ - Bauru } & $-0,0024$ & 0,0487 & $-0,0092$ & 0,0513 & - \\
\hline & $(0,0180)$ & $(0,0696)$ & $(0,0174)$ & $(0,1186)$ & - \\
\hline \multirow[t]{2}{*}{ - Araraquara } & $-0,2624 *$ & $-0,1226 * * *$ & $-0,2403$ & $-0,2684$ & - \\
\hline & $(0,1386)$ & $(0,0390)$ & $(0,1671)$ & $(0,2684)$ & - \\
\hline \multirow[t]{2}{*}{ - Piracicaba } & $-0,2153^{\star \star \star}$ & $-0,1449 * \star$ & $-0,1935 * * *$ & $-0,1025$ & - \\
\hline & $(0,0498)$ & $(0,0602)$ & $(0,0413)$ & $(0,1861)$ & - \\
\hline \multirow{2}{*}{ - Campinas } & $0,2677^{* *}$ & 0,1970 & $0,2355^{* * *}$ & 0,1877 & - \\
\hline & $(0,1238)$ & $(0,1417)$ & $(0,0848)$ & $(0,1308)$ & - \\
\hline \multirow[t]{2}{*}{ - Presidente Prudente } & $-0,0092$ & 0,0070 & $-0,1415$ & $-0,1216$ & - \\
\hline & $(0,1640)$ & $(0,1578)$ & $(0,1081)$ & $(0,1337)$ & - \\
\hline \multirow[t]{2}{*}{ - Marília } & $-0,3174$ & $-0,7016 * * *$ & $-0,5362$ & $-0,4900$ & - \\
\hline & $(0,3796)$ & $(0,1136)$ & $(0,3606)$ & $(0,3660)$ & - \\
\hline \multirow[t]{2}{*}{ - Assis } & $-0,0768 * \star \star$ & $-0,0081$ & $-0,0785^{* \star *}$ & $-0,1323$ & - \\
\hline & $(0,0243)$ & $(0,1077)$ & $(0,0283)$ & $(0,2342)$ & - \\
\hline \multirow[t]{2}{*}{ - Itapetininga } & 0,3743 & 0,0325 & 0,4144 & $0,4274 * *$ & - \\
\hline & $(0,2471)$ & $(0,1140)$ & $(0,3487)$ & $(0,1744)$ & - \\
\hline \multirow{2}{*}{$\begin{array}{l}\text { - Macro Metropolitana } \\
\text { Paulista }\end{array}$} & $-0,0394$ & $-0,0760 * * *$ & $-0,0382$ & $-0,0353$ & - \\
\hline & $(0,0706)$ & $(0,0146)$ & $(0,0411)$ & $(0,0725)$ & - \\
\hline \multicolumn{6}{|c|}{ Precipitação } \\
\hline \multirow[t]{2}{*}{ - São José do Rio Preto } & $0,1696 * \star$ & $0,1693 * \star$ & - & $0,0287 * *$ & $0,1757^{* * *}$ \\
\hline & $(0,0651)$ & $(0,0636)$ & - & $(0,0142)$ & $(0,0643)$ \\
\hline \multirow[t]{2}{*}{ - Ribeirão Preto } & 0,0157 & $-0,0013$ & - & 0,0108 & 0,0023 \\
\hline & $(0,0547)$ & $(0,0520)$ & - & $(0,0155)$ & $(0,0468)$ \\
\hline \multirow[t]{2}{*}{ - Araçatuba } & 0,0919 & 0,0913 & - & $-0,0095$ & 0,0754 \\
\hline & $(0,0752)$ & $(0,0786)$ & - & $(0,0371)$ & $(0,0784)$ \\
\hline \multirow[t]{2}{*}{ - Bauru } & 0,0330 & 0,0437 & - & $-0,0238$ & 0,0337 \\
\hline & $(0,0262)$ & $(0,0260)$ & - & $(0,0258)$ & $(0,0254)$ \\
\hline \multirow[t]{2}{*}{ - Araraquara } & $0,1506 * * *$ & $0,2415^{* * *}$ & - & $-0,0558$ & $0,1270 * *$ \\
\hline & $(0,0247)$ & $(0,0228)$ & - & $(0,1094)$ & $(0,0485)$ \\
\hline \multirow[t]{2}{*}{ - Piracicaba } & $-0,0574 * *$ & $-0,0409$ & - & 0,0298 & $-0,0321$ \\
\hline & $(0,0279)$ & $(0,0307)$ & - & $(0,0486)$ & $(0,0367)$ \\
\hline \multirow[t]{2}{*}{ - Campinas } & 0,0753 & 0,0617 & - & 0,0183 & $-0,0243$ \\
\hline & $(0,1084)$ & $(0,1081)$ & - & $(0,0130)$ & $(0,0468)$ \\
\hline \multirow[t]{2}{*}{ - Presidente Prudente } & 0,1471 ** & $0,1485^{\star *}$ & - & $-0,0530$ & $0,1504^{* * *}$ \\
\hline & $(0,0618)$ & $(0,0570)$ & - & $(0,0710)$ & $(0,0314)$ \\
\hline - Marília & $0,1615^{* * *}$ & 0,1116 & - & $0,0608 *$ & $0,2157 * * *$ \\
\hline & $(0,0290)$ & $(0,0757)$ & - & $(0,0313)$ & $(0,0109)$ \\
\hline
\end{tabular}

Desvio padrão entre parênteses. * $p<0,10, * \star p<0,05, * * * p<0,01$. Fonte: Resultados da pesquisa. 
Tabela 1 - Continuação...

\begin{tabular}{|c|c|c|c|c|c|}
\hline & 1 & 2 & 3 & 4 & 5 \\
\hline \multicolumn{6}{|c|}{ Precipitação } \\
\hline \multirow[t]{2}{*}{ - Assis } & $-0,0022$ & $-0,0177$ & - & 0,0122 & $-0,0105^{*}$ \\
\hline & $(0,0095)$ & $(0,0128)$ & - & $(0,0389)$ & $(0,0059)$ \\
\hline \multirow[t]{2}{*}{ - Itapetininga } & $-0,1499$ & $-0,1814$ & - & $-0,0498 * * *$ & $-0,1829$ \\
\hline & $(0,1785)$ & $(0,2301)$ & - & $(0,0163)$ & $(0,2332)$ \\
\hline \multirow{2}{*}{$\begin{array}{l}\text { - Macro Metropolitana } \\
\text { Paulista }\end{array}$} & $0,0866^{*}$ & 0,0865 & - & $-0,0390 * *$ & 0,0861 \\
\hline & $(0,0455)$ & $(0,0727)$ & - & $(0,0164)$ & $(0,0553)$ \\
\hline \multicolumn{6}{|c|}{ Trabalho } \\
\hline \multirow[t]{2}{*}{ - São José do Rio Preto } & $0,0709^{* *}$ & $0,0702 * \star$ & 0,0601 * & $-0,0143$ & $0,0569 * *$ \\
\hline & $(0,0311)$ & $(0,0298)$ & $(0,0308)$ & $(0,0087)$ & $(0,0280)$ \\
\hline \multirow[t]{2}{*}{ - Ribeirão Preto } & 0,0353 & 0,0273 & 0,0358 & $-0,0039$ & 0,0179 \\
\hline & $(0,0236)$ & $(0,0253)$ & $(0,0223)$ & $(0,0115)$ & $(0,0310)$ \\
\hline \multirow[t]{2}{*}{ - Araçatuba } & 0,1868 & 0,1912 & 0,0830 & 0,0186 & $0,1437 * \star$ \\
\hline & $(0,1354)$ & $(0,1357)$ & $(0,0987)$ & $(0,0390)$ & $(0,0689)$ \\
\hline \multirow[t]{2}{*}{ - Bauru } & $0,0331 * * *$ & $0,0249 *$ & $0,0390 * * *$ & 0,0230 & $0,0330 * * *$ \\
\hline & $(0,0114)$ & $(0,0146)$ & $(0,0127)$ & $(0,0231)$ & $(0,0107)$ \\
\hline \multirow[t]{2}{*}{ - Araraquara } & $-0,0536 * * *$ & $-0,4944 * * *$ & $0,1776 * *$ & 0,0734 & $0,2171 * * *$ \\
\hline & $(0,0095)$ & $(0,1024)$ & $(0,0813)$ & $(0,1164)$ & $(0,0679)$ \\
\hline \multirow[t]{2}{*}{ - Piracicaba } & $-0,0686 * \star \star$ & $-0,0845^{* *}$ & $-0,0580^{*}$ & $-0,0274$ & 0,0331 \\
\hline & $(0,0123)$ & $(0,0376)$ & $(0,0291)$ & $(0,0443)$ & $(0,0413)$ \\
\hline \multirow[t]{2}{*}{ - Campinas } & $-0,1194$ & $-0,1050$ & $-0,1232$ & $-0,0256 * *$ & $-0,0926$ \\
\hline & $(0,0922)$ & $(0,0793)$ & $(0,1022)$ & $(0,0108)$ & $(0,0720)$ \\
\hline \multirow[t]{2}{*}{ - Presidente Prudente } & $0,3777 * \star \star$ & $0,3350 * * *$ & $0,3175^{* * *}$ & 0,0702 & $0,3821 * * *$ \\
\hline & $(0,1214)$ & $(0,1185)$ & $(0,1110)$ & $(0,0768)$ & $(0,0829)$ \\
\hline \multirow[t]{2}{*}{ - Marília } & $-0,0144$ & 0,0322 & $-0,0129$ & $-0,0199$ & $-0,0239$ \\
\hline & $(0,0959)$ & $(0,0339)$ & $(0,0669)$ & $(0,0281)$ & $(0,1010)$ \\
\hline \multirow[t]{2}{*}{ - Assis } & $0,0458 * \star \star$ & 0,0346 & $0,0453 * * *$ & $-0,0083$ & $0,1018 *$ \\
\hline & $(0,0119)$ & $(0,0364)$ & $(0,0122)$ & $(0,0392)$ & $(0,0534)$ \\
\hline \multirow[t]{2}{*}{ - Itapetininga } & $0,0262 * \star *$ & 0,0092 & 0,0103 & $0,0514 * \star *$ & $-0,0153$ \\
\hline & $(0,0094)$ & $(0,0317)$ & $(0,0136)$ & $(0,0147)$ & $(0,0215)$ \\
\hline \multirow{2}{*}{$\begin{array}{l}\text { - Macro Metropolitana } \\
\text { Paulista }\end{array}$} & $-0,1613$ & $-0,1633$ & $-0,1569$ & $0,0402 * \star *$ & $-0,1608$ \\
\hline & $(0,1024)$ & $(0,1160)$ & $(0,1128)$ & $(0,0133)$ & $(0,1016)$ \\
\hline Tendência linear & heterog. & homog. & heterog. & heterog. & heterog. \\
\hline Efeito fixo & Sim & Sim & Sim & Não & Sim \\
\hline$N$ & 320 & 320 & 320 & 320 & 320 \\
\hline r2 & 0,3641 & 0,2765 & 0,3178 & 0,3634 & 0,3215 \\
\hline
\end{tabular}

Desvio padrão entre parênteses. * $p<0,10, * * p<0,05, * * * p<0,01$. Fonte: Resultados da pesquisa.

A comparação entre as especificações evidenciou a relevância de considerar efeitos heterogêneos da mecanização entre as mesorregiões e, também, dos controles para a estimação dos efeitos da mecanização, sobretudo dos efeitos fixos para microrregiões. Esse resultado era esperado tendo em vista que a produtividade agrícola é influenciada por características biofísicas locais, como qualidade do solo, potencial de erosão, disponibilidade de água e comportamento climático, e por características do sistema produtivo, envolvendo aspectos como tamanho das propriedades, gestão, uso de tecnologia e de insumos, que também são heterogêneas no espaço; e que a produtividade da colheitadeira também depende de fatores como declividade, variedade adequada para colheita com máquina, sistematização da área e prática do operador da colhedora, que devem variar no espaço (Gornall et al., 2010; Torquato, 2013). 
Considerando o modelo completo (coluna 1), foram estimados efeitos negativos do avanço da mecanização sobre a produtividade para as seguintes mesorregiões: Ribeirão Preto, Araraquara, Piracicaba e Assis, com o efeito relativo mais intenso observado em Araraquara. Já em Campinas, estimou-se coeficiente positivo.

Considerando os efeitos da mecanização apresentados na Tabela 1 e a evolução da participação da área com colheita mecanizada na área total de cada mesorregião, tem-se a perda agregada de produtividade no período. Na Tabela 2, tem-se o cálculo da perda (ou ganho) agregada para as mesorregiões e, na Figura 6, apresenta-se o resultado agregado para as regiões com impacto significativo.

Tabela 2 - Para as mesorregiões de São Paulo: evolução da área e da participação de áreas com colheita mecanizada e impactos da mecanização

\begin{tabular}{|c|c|c|c|c|c|c|c|}
\hline \multirow[b]{2}{*}{ Mesorregião } & \multicolumn{2}{|c|}{ Área (mil ha) } & \multicolumn{2}{|c|}{ \% mecanização } & \multicolumn{3}{|c|}{ Impacto da mecanização } \\
\hline & 2007 & 2013 & 2007 & 2013 & $\boldsymbol{\beta}_{1 j}$ & $\begin{array}{c}\Delta \% \\
\text { mecan. }\end{array}$ & $\begin{array}{c}\text { Perda } \\
\text { agregada }\end{array}$ \\
\hline São José do Rio Preto & 545 & 970 & $45 \%$ & $84 \%$ & $-0,164$ & 38 p.p. & \\
\hline Ribeirão Preto & 1.175 & 1.319 & $45 \%$ & $80 \%$ & $-0,188 * * *$ & 35 p.p. & $-6,6 \%$ \\
\hline Araçatuba & 346 & 509 & $48 \%$ & $90 \%$ & 0,084 & 42 p.p. & \\
\hline Bauru & 438 & 625 & $42 \%$ & $83 \%$ & $-0,002$ & 41 p.p. & \\
\hline Araraquara & 298 & 382 & $54 \%$ & $91 \%$ & $-0,262^{*}$ & 37 p.p. & $-9,7 \%$ \\
\hline Piracicaba & 276 & 313 & $56 \%$ & $85 \%$ & $-0,215 * \star \star *$ & 29 р.p. & $-6,2 \%$ \\
\hline Campinas & 226 & 249 & $54 \%$ & $80 \%$ & $0,268 * *$ & 26 p.p. & $7 \%$ \\
\hline Presidente Prudente & 224 & 525 & $51 \%$ & $86 \%$ & $-0,009$ & 35 p.p. & \\
\hline Marília & 24 & 71 & $73 \%$ & $89 \%$ & $-0,317$ & 16 p.p. & \\
\hline Assis & 272 & 338 & $35 \%$ & $80 \%$ & $-0,077 * \star$ & 45 р.p. & $-3,5 \%$ \\
\hline Itapetininga & 47 & 73 & $44 \%$ & $80 \%$ & 0,374 & 35 p.p. & \\
\hline $\begin{array}{l}\text { Macro Metropolitana } \\
\text { Paulista }\end{array}$ & 20 & 23 & $63 \%$ & $71 \%$ & $-0,039$ & 7 p.p. & \\
\hline
\end{tabular}

Fonte: Resultados da pesquisa

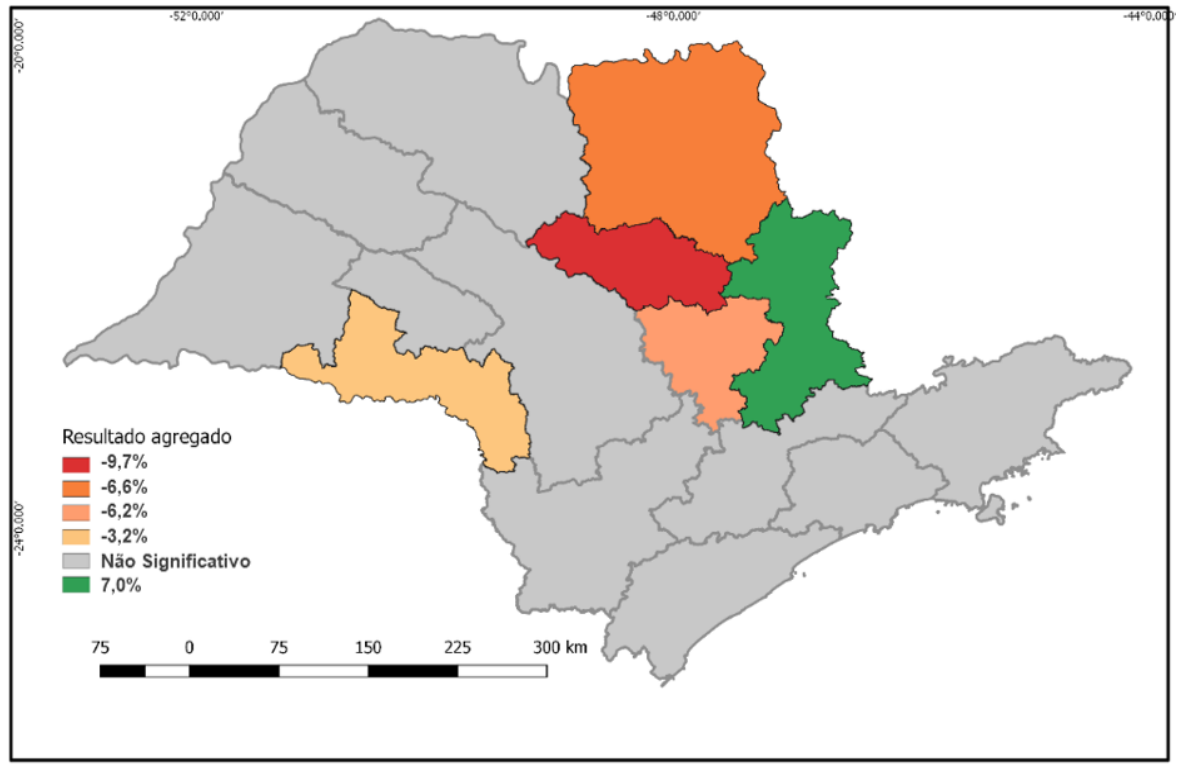

Figura 6 - Resultado agregado do impacto sobre a produtividade da terra em (\%) para o período de 2007 a 2013. Fonte: Resultados da pesquisa. 
Os resultados apresentados na Tabela 2 e na Figura 6 estão alinhados com os de Miranda et al. (2014), que identificaram as áreas de São Paulo em situação crítica diante do avanço da mecanização, considerando as declividades das áreas e a proporção da cana-de-açúcar de cada região em declivosas. Os resultados desses autores constam na Figura 7, que indica os municípios mais críticos na relação cana-de-açúcar versus declividade. Nota-se que os impactos significativos encontrados nesse trabalho foram estimados para mesorregiões com áreas bastante coincidentes aos municípios críticos identificados por Miranda et al. (2014).

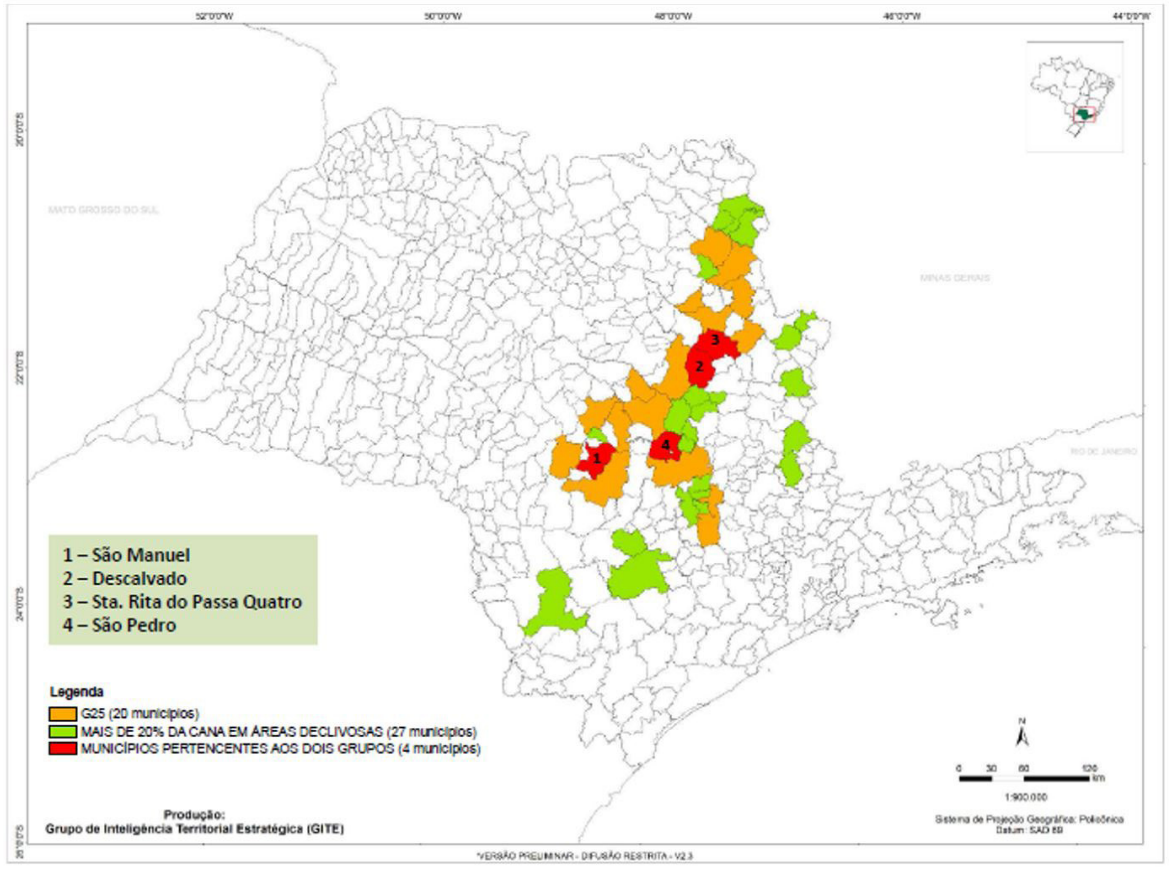

Figura 7 - Municípios mais críticos na relação cana-de-açúcar versus declividade. Fonte: Miranda et al. (2014, p. 49).

Deve-se enfatizar que essas mesorregiões - Ribeirão Preto, Araraquara, Piracicaba e Assis -, nas quais foram encontrados impactos negativos significativos da mecanização, o que provavelmente se deve à declividade das áreas com cana (Miranda et al., 2014), não estão entre aquelas para as quais a produtividade caiu com mais intensidade no período, à exceção de Ribeirão Preto. Segundo dados da PAM-IBGE (Instituto Brasileiro de Geografia e Estatística, 2018), na comparação entre os biênios de 2007-2008 e 2012-2013, a produtividade média reduziu 3,19\% em Piracicaba e 3,92\% em Assis, e aumentou 0,67\% em Araraquara. Já em Ribeirão Preto, reduziu 7,06\%, o que em grande medida deve ter refletido o efeito da mecanização que, conforme apresentado na Tabela 2, contribuiu para uma queda acumulada de 6,6\% na produtividade.

Considerando a representatividade de cada região na produção canavieira do estado e a dinâmica das produtividades regionais no período, a queda da produtividade agregada observada no estado reflete sobretudo os comportamentos para Ribeirão Preto, São José do Rio Preto, Araçatuba e Presidente Prudente. Para São José do Rio Preto, a produtividade reduziu 7,99\% na comparação entre os biênios; para Araçatuba, reduziu 9,17\%, e para Presidente Prudente, 13,45\% (Instituto Brasileiro de Geografia e Estatística, 2018). No caso dessas três últimas, embora tenha havido redução de produtividade no período, essa não foi devida à mecanização. Essas regiões se concentram no noroeste paulista, de expansão mais recente - intensificada apenas a partir dos anos 2000, segundo Camara \& Caldarelli (2016). 
Conforme Koga-Vicente et al. (2013), a intensificação da expansão da cana para regiões como Araçatuba e Presidente Prudente reflete, inclusive, as regulamentações de datas para a extinção da queimada na colheita. Os autores apontam que, diante da disponibilidade limitada de colheitadeiras no que tange à declividade das áreas, por situarem-se em áreas compostas predominantemente por planaltos e planícies sedimentares, as regiões central e oeste do estado se tornaram mais adequadas. Isso, apesar de apresentarem uma aptidão do solo inferior à das áreas tradicionais, conforme apresentado em Marin \& Carvalho (2012).

Então, há duas perspectivas distintas quanto à associação entre o avanço do processo de mecanização e a queda de fato ocorrida na produtividade no estado, pressionada pelos resultados sobretudo em Ribeirão Preto, São José do Rio Preto, Araçatuba e Presidente Prudente. Por um lado, a mecanização teve efeitos negativos importantes diretos sobre a produtividade em Ribeirão Preto, mesorregião responsável por $25 \%$ do volume produzido de cana no biênio 2012-2013. Por outro lado, quedas importantes e não associadas diretamente à mecanização foram observadas no noroeste paulista (São José do Rio Preto, Araçatuba e Presidente Prudente). Essas regiões, não consideradas por Miranda et al. (2014) como críticas no que tange ao avanço da mecanização, responderam por 37\% do volume produzido de cana no biênio 2012-2013. Portanto, a expansão para essas regiões menos aptas ao cultivo e com menor produtividade poderia se configurar como um efeito indireto da necessidade de mecanização, mas os dados e o modelo avaliados neste presente estudo não permitem tal avaliação.

Importante destacar que o impacto negativo da mecanização possivelmente será reduzido à medida em que se desenvolve o processo de aprendizagem no âmbito da produção. Nyko et al. (2013) ressaltam que os efeitos negativos da mecanização sobre a produtividade da cana-deaçúcar apontados por especialistas podem estar relacionados ao fato de que o processo de mecanização da cultura, diferente do que se observou para os cereais, é recente, encontrandose em estágio de adaptação e aprimoramento.

Deve-se ressaltar, como mostram Milanez et al. (2012), que a tendência apontada por especialistas de redução da produtividade diante da mecanização, observada especialmente em São Paulo, pode ser revertida à medida que os produtores se adaptarem às novas condições, atingindo os níveis de conhecimento e destreza necessários. Alternativas tecnológicas vêm surgindo para o emprego de implementos de corte mecânico para áreas em declive maior que $12 \%$, com maior uso de mão de obra que a mecanização convencional da colheita (Braunbeck \& Oliveira, 2006). No entanto, ainda são tecnologias minoritárias no uso e ainda em fase de implementação e análise de viabilidade. Importante destacar, porém, que o desenvolvimento tecnológico em melhorias produtivas requer grandes investimentos, e o setor ainda sofre com alto nível de endividamento e redução de margens, o que pode prejudicar ações nesse sentido.

\section{CONCLUSÕES}

No período estudado, de 2007 a 2013, o percentual de área mecanizada passou de 46,6\% para $83,7 \%$, e se verificou queda da produtividade na ordem de $5 \%$. Os resultados do estudo apontaram para a existência de um impacto negativo do avanço da mecanização para quatro mesorregiões do estado de São Paulo - a citar: 6,6\% em Ribeirão Preto, 9,7\% em Araraquara, $6,2 \%$ em Piracicaba e 3,4\% em Assis, envolvendo as mais tradicionais regiões produtoras do estado. Essas regiões têm parte relevante da área canavieira localizada em áreas declivosas. Para outras regiões, como São José do Rio Preto, Araçatuba e Presidente Prudente, para as quais também houve redução de produtividade no período, não foram encontrados impactos significativos da mecanização. 
Então, por um lado, a mecanização teve efeitos negativos importantes sobre a produtividade em Ribeirão Preto, principal mesorregião produtora do estado. Por outro, quedas importantes e não associadas à mecanização foram observadas em importantes mesorregiões produtoras do noroeste paulista e de expansão mais recente - São José do Rio Preto, Araçatuba e Presidente Prudente.

Destaca-se que o choque tecnológico relacionado à necessidade de mecanização ainda pode reverter o resultado de queda na produtividade encontrado com o processo de evolução das tecnologias e com o aprendizado com relação às práticas de cultivo mais adaptadas ao modelo mecanizado. No entanto, é importante que o setor tenha capacidade e previsibilidade com relação aos investimentos para que esse processo seja concluído e que isso se reflita em resultados positivos, sendo este um grande desafio para os agentes públicos e privados relacionados ao desenvolvimento dessa cadeia de produção.

\section{REFERÊNCIAS}

Aguiar, D. A., Rudorff, B. F. T., Silva, W. F., Adami, M., \& Mello, M. P. (2011). Remote sensing images in support of environmental protocol: monitoring the sugarcane harvest in São Paulo State, Brazil. Remote Sensing, 3(12), 2682-2703. http://dx.doi.org/10.3390/rs3122682

Aguilera Esteban, D. A., Souza, Z. M., Tormena, C. A., Lovera, L. H., de Souza Lima, E., de Oliveira, I. N., \& de Paula Ribeiro, N. (2019). Soil compaction, root system and productivity of sugarcane under different row spacing and controlled traffic at harvest. Soil \& Tillage Research, 187, 60-71. http://dx.doi.org/10.1016/j.still.2018.11.015

Auffhammer, M., Ramanathan, V., \& Vincent, J. R. (2012). Climate change, the monsoon, and rice yield in India. Climatic Change, 111(2), 411-424. http://dx.doi.org/10.1007/s10584-011-0208-4

Baccarin, J. G. (2015). Mudanças tecnológicas recentes e ocupação canavieira no centro sul do Brasil. Revista Laborativa, 4(1), 56-78.

Brasil. (1998, julho 9). Decreto n².661, de 8 de julho de 1998. Diário Oficial [da] República Federativa do Brasil, Brasília.

Brasil. Ministério do Trabalho e Emprego - MTE. (2020). Relação Anual de Informações Sociais ação Anual de Informações Sociais - RAIS. Brasília.

Braunack, M. V., \& McGarry, D. (2006). Traffic control and tillage strategies for harvesting and planting of sugarcane (Saccharum officinarum) in Australia. Soil \& Tillage Research, 89(1), 86-102. http://dx.doi.org/10.1016/j.still.2005.07.002

Braunbeck, O.A., \& Oliveira, J.T. (2006). Colheita de cana-de-açúcar com auxílio mecânico. Engenharia Agrícola, 26(1), 300-308.

Caldarelli, C. E., \& Gilio, L. (2018). Expansion of the sugarcane industry and its effects on land use in São Paulo: Analysis from 2000 through 2015. Land Use Policy, 76, 264-274. http:// dx.doi.org/10.1016/j.landusepol.2018.05.008

Camara, M. R. G. D., \& Caldarelli, C. E. (2016). Expansão canavieira e o uso da terra no estado de São Paulo. Estudos Avançados, 3088), 93-116. http://dx.doi.org/10.1590/s0103-40142016.30880008

Cameron, A. C., \& Trivedi, P. K. (2005). Microeconometrics: methods and applications. Cambridge: Cambridge University Press.

CANASAT (2019). Monitoramento da Cana-de-açúcar via imagens de satélite. Recuperado em 20 de novembro de 2019, de http://www.dsr.inpe.br/laf/canasat/ 
Cardoso, T. F., Watanabe, M. D., Souza, A., Chagas, M. F., Cavalett, O., Morais, E. R., Nogueira, L. A. H., Leal, M. R. L. V., Braunbeck, O. A., Cortez, L. A. B., \& Bonomi, A. (2018). Economic, environmental, and social impacts of different sugarcane production systems. Biofuels, Bioproducts \& Biorefining, 12(1), 68-82. http://dx.doi.org/10.1002/bbb.1829

Companhia Nacional de Abastecimento - CONAB. (2019). Série histórica das safras. Grãos: por unidades da federação. Recuperado em 20 de novembro de 2020, de https://www.conab. gov.br/info-agro/safras/serie-historica-das-safras

Conselho de Produtores de Cana-de-Açúcar, Açúcar e Etanol do Estado de São Paulo - CONSECANA. (2020). Circulares $n^{\circ} 1 / 07$ a $n^{\circ}$ 18/13. Recuperado em 20 de novembro de 2020, de https:// www.udop.com.br/index.php?item=consecana_sp\&op=index

Dias, H. B., \& Sentelhas, P. C. (2018). Sugarcane yield gap analysis in Brazil: a multi-model approach for determining magnitudes and causes. The Science of the Total Environment, 637-638, 1127-1136. http://dx.doi.org/10.1016/j.scitotenv.2018.05.017

Dlamini, M. B., \& Masuku, M. B. (2012). Productivity of Smallholder Sugarcane Farmers in Swaziland: The Case of Komati Downstream Development Programme (KDDP) Farmers' Associations, 20052011. Environment and Natural Resources Research, 2(4), 1. http://dx.doi.org/10.5539/enrr.v2n4p1

Gilio, L. (2015). Análise dos impactos socioeconômicos da expansão do setor sucroenergético (Doctoral dissertation). Universidade de São Paulo. http://dx.doi.org/10.11606/D.11.2015. tde-22042015-143758.

Gilio, L., \& Castro, N. R. (2017). Avaliação de aspectos limitantes ao crescimento do etanol e o setor sucroenergético no Brasil. Revista Eletrônica de Energia, 6(1).

Gilio, L., Castro, N. R., Rodrigues, L., \& Bacchi, M. R. P. (2019). Mercado de trabalho formal e rendimentos da agroindústria sucroenergética de 2000 a 2016. Economia Aplicada, 23(4), 93-112. http://dx.doi.org/10.11606/1980-5330/ea151478

Gilio, L., Moraes, M. A. F. D., Moreira, G. C., \& Guardia, A. F. T. S. (2015). Restrição à propriedade e arrendamento de terras por estrangeiros: evidências sobre efeitos nas decisões de investimento do setor sucroenergetico. Economic Analysis of Law Review, 6(2), 356-372. http://dx.doi.org/10.18836/2178-0587/ealr.v6n2p356-372

Gornall, J., Betts, R., Burke, E., Clark, R., Camp, J., Willett, K., \& Wiltshire, A. (2010). Implications of climate change for agricultural productivity in the early twenty-first century. Philosophical Transactions of the Royal Society of London. Series B, Biological Sciences, 365(1554), 29732989. http://dx.doi.org/10.1098/rstb.2010.0158

Hayami, Y., \& Ruttan, V. W. (1970). Agricultural productivity differences among countries. The American Economic Review, 60(5), 895-911.

Instituto Brasileiro de Geografia e Estatística - IBGE. (2018). Levantamento sistemático da produção agrícola: pesquisa agrícola municipal. Rio de Janeiro. Recuperado em 20 de setembro de 2020, de https://www.ibge.gov.br/estatisticas/todos-os-produtos-estatisticas.html\#download

Koga-Vicente, A., Zullo Junior, J., \& Aidar, T. (2013). Evolução da produção da cana-de-açúcar em regiões canavieiras tradicionais e em expansão do estado de São Paulo. In R. Baeninger, J. Zullo Junior, T. Aidar \& R. G. Perez (Eds.), Regiões canavieiras. Campinas: UNICAMP.

Kumar, A., Sharma, P., \& Ambrammal, S. K. (2015). Climatic effects on sugarcane productivity in India: A stochastic production function application. International Journal of Economics and Business Research, 10(2), 179-203. http://dx.doi.org/10.1504/JEBR.2015.070984 
Levinsohn, J., \& Petrin, A. (2003). Estimating production functions using inputs to control for unobservables. The Review of Economic Studies, 70(2), 317-341. http://dx.doi. org/10.1111/1467-937X.00246

Marin, F. R., \& Carvalho, G. L. D. (2012). Spatio-temporal variability of sugarcane yield efficiency in the state of São Paulo, Brazil. Pesquisa Agropecuária Brasileira, 47(2), 149-156. http:// dx.doi.org/10.1590/S0100-204X2012000200001

Marin, F. R., Martha Junior, G. B., Cassman, K. G., \& Grassini, P. (2016). Prospects for increasing sugarcane and bioethanol production on existing crop area in Brazil. Bioscience, 66(4), 307-316. http://dx.doi.org/10.1093/biosci/biw009

McArthur, J. W., \& McCord, G. C. (2017). Fertilizing growth: agricultural inputs and their effects in economic development. Journal of Development Economics, 127, 133-152. http://dx.doi. org/10.1016/j.jdeveco.2017.02.007

Milanez, A. Y., Nyko, D., Garcia, J. L. F., \& Reis, B. L. S. F. S. D. (2012). O déficit de produção de etanol no Brasil entre 2012 e 2015: determinantes, consequências e sugestões de política. BNDES Setorial, (35), 277-302.

Miranda, E. E.., Carvalho, C. A., Daltio, J., Mangabeira, J. A.C., Magalhães, L.A., Fonseca, M. F., Martinho, P.R.R., \& Seraphim, Y. C. S.S. (2014). Impacto da mecanização da colheita da cana-de-açúcar nas áreas declivosas do estado de São Paulo. Recuperado em 20 de junho de 2019, de https://www.fiesp.com.br/arquivo-download/?id=173693

Moraes, M. A. F. D. (2007). O mercado de trabalho da agroindústria canavieira: desafios e oportunidades. Economia Aplicada, 11(4), 605-619. http://dx.doi.org/10.1590/S1413-80502007000400008.

Moraes, M. A. F. D., \& Zilberman, D. (2014). Production of ethanol from sugarcane in Brazil: from state intervention to a free market(Vol. 43). Springer Science \& Business Media. http:// dx.doi.org/10.1007/978-3-319-03140-8

Mundlak, Y. (2001). Production and supply. In B. Gardner \& G. Rausser (Eds.), Handbook of agricultural economics (Vol. 1, pp. 3-85). Amsterdam: Elsevier.

Nazir, A., Jariko, G. A., \& Junejo, M. A. (2013). Factors affecting sugarcane production in Pakistan. Pakistan Journal of Commerce and Social Sciences, $7(1), 128-140$.

Nyko, D., Valente, M. S., Milanez, A. Y., Tanaka, A. K. R., \& Rodrigues, A. V. P. (2013). A evolução das tecnologias agrícolas do setor sucroenergético: estagnação passageira ou crise estrutural? BNDES Setorial, (37), 399-442.

Otto, R., Silva, A. D., Franco, H. C. J., Oliveira, E. D., \& Trivelin, P. C. O. (2011). High soil penetration resistance reduces sugarcane root system development. Soil \& Tillage Research, 117, 201 210. http://dx.doi.org/10.1016/j.still.2011.10.005

Rudorff, B. F. T., Aguiar, D. A., Silva, W. F., Sugawara, L. M., Adami, M., \& Moreira, M. A. (2010). Studies on the rapid expansion of sugarcane for ethanol production in São Paulo State (Brazil) using Landsat data. Remote Sensing, 2(4), 1057-1076. http://dx.doi.org/10.3390/rs2041057

Sachs, R. C. C. (2015). Contribuição das inovações biológicas para a produtividade da canade-açúcar no estado de São Paulo, 1998-2009 (Doctoral dissertation). Universidade de São Paulo. Recuperado em 20 de setembro de 2020, de https://www.teses.usp.br/teses/ disponiveis/11/11132/tde-29092015-153408/publico/Raquel_Castellucci_Caruso_Sachs.pdf

Santos, G. R. D., Garcia, E. A., \& Shikida, P. F. A. (2015). A crise na produção do etanol e as interfaces com as políticas públicas. Recuperado em 20 de junho de 2020, de http:// repositorio.ipea.gov.br/handle/11058/4259 
Satolo, L. F., \& Bacchi, M. R. P. (2009). Dinâmica econômica das flutuações na produção de cana-de-açúcar. Economia Aplicada, 13(3), 377-397. http://dx.doi.org/10.1590/S141380502009000300002

Scheidl, H. A., Simon, A. T., Pacagnella Junior, A. C., \& Salgado Júnior, A. P. (2015). Environmental impacts of mechanization in Brazil's sugar and ethanol industry: The cutting, loading, and transportation process case. Environmental Progress \& Sustainable Energy, 34(6), 17481755. http://dx.doi.org/10.1002/ep.12159

Schmitz, A., \& Zhang, F. (2019). The dynamics of sugarcane and sugar yields in Florida: 1950-2018. Crop Science, 59(5), 1880-1886. http://dx.doi.org/10.2135/cropsci2018.11.0674

Schmitz, A., Kennedy, P. L., \& Zhang, F. (2020). Sugarcane and sugar yields in Louisiana (19112018): Varietal development and mechanization. Crop Science, 60(3), 1303-1312. http:// dx.doi.org/10.1002/csc2.20045

Silva, H. J. T., \& Marques, P. V. (2017). Evolution of production costs in Brazilian sugar-energy sector. China-USA Business Review, 16(3). http://dx.doi.org/10.17265/1537-1514/2017.03.001.

Silva, R. P., Gilio, L., \& Castro, N. R. (2019). Impactos da eliminação da queimada da cana sobre o setor sucroenergético: uma análise de equilíbrio geral. Revista Economica do Nordeste, 5Q(1), 9-21.

Solowiejczyk, A., \& Costa, R. P. F. (2013). O controle de preço da gasolina pode ser fatal. AgroANALYSIS, 33(2), 21-23.

Souza, G. S. D., Souza, Z. M. D., Silva, R. B. D., Barbosa, R. S., \& Araújo, F. S. (2014). Effects of traffic control on the soil physical quality and the cultivation of sugarcane. Revista Brasileira de Ciência do Solo, 38(1), 135-146. http://dx.doi.org/10.1590/S0100-06832014000100013

Toneto-Junior, R., \& Liboni, L. B. (2008). Evolução recente do mercado de trabalho da cana-deaçúcar no brasil (1995-2006). Organizações Rurais \& Agroindustriais, 10(3), 455-474.

Torquato, S. A. (2013). Mecanização da colheita da cana-de-açúcar: benefícios ambientais e impactos na mudança do emprego no campo em São Paulo, Brasil. Brazilian Journal of Environmental Sciences, 29, 49-62.

Tullberg, J. N., Yule, D. F., \& McGarry, D. (2007). Controlled traffic farming: from research to adoption in Australia. Soil \& Tillage Research, 972), 272-281. http://dx.doi.org/10.1016/j.still.2007.09.007

Usaborisut, P., \& Sukcharoenvipharat, W. (2011). Soil compaction in sugarcane fields induced by mechanization. American Journal of Agricultural and Biological Sciences, 6(3), 418-422. http://dx.doi.org/10.3844/ajabssp.2011.418.422

Xavier, A. C., King, C. W., \& Scanlon, B. R. (2016). Daily gridded meteorological variables in Brazil (19802013). InternationalJournal of Climatology, 36(6), 2644-2659. http://dx.doi.org/10.1002/joc.4518 